\title{
A randomized treatment study to compare the efficacy of repeated nerve blocks with cognitive therapy for control of chronic head and neck pain
}

\author{
George Gale MBBS FRCA DAAPM ${ }^{1}$, David Nussbaum PhD C Psych², \\ Peter Rothbart MD FRCPC ${ }^{1}$, Beverley Hann RN MBA MA ${ }^{1}$, \\ Van Leung $\mathrm{BA}^{3}$, Gillian Kanetz $\mathrm{BA}^{3}$
}

G Gale, D Nussbaum, P Rothbart, B Hann, V Leung, $G$ Kanetz. A randomized treatment study to compare the efficacy of repeated nerve blocks with cognitive therapy for control of chronic head and neck pain. Pain Res Manage 2002;7(4):185-189.

This prospective study compared the efficacy of two antinociceptive modalities: nerve blocks and cognitive therapy. A consecutive series of patients receiving nerve block therapy was invited to take part in a six-week randomized comparison of nerve blocks and cognitive therapy. Sixty-eight of 102 patients approached by telephone agreed to participate. Patients attended eight weekly treatment sessions. Baseline and seven weekly sets of values were recorded. The principal measure of outcome was the Pain on a Visual Analogue Scale (VAS). The secondary measures were the Hospital Anxiety and Depression Scale, and the Activities of Daily Living as measured on the Primary Care Cooperative Information Project/World Organization of National Colleges, Academies (COOP-WONCA) scale. Within the first week, one patient of 34 in the nerve block group withdrew and 12 of 34 in the cognitive therapy group withdrew from the study. After seven weeks, 33 patients in the nerve block group remained in the trial, but only 21 patients completed the questionnaires. Four of 22 patients in the cognitive therapy group completed the trial and their questionnaires. Mean VAS scores in the nerve block group dropped slightly during treatment. Mean VAS scores in the cognitive therapy group rose during the trial. However, the mean VAS score of the remaining four in the last week was below the initial group mean. Patients who had been receiving nerve blocks proved willing to remain in the study if allocated to the nerve block group and unwilling to remain in the cognitive therapy group while foregoing their accustomed treatment.

Key Words: Antinociceptive; Cervicogenic headache; Cognitive therapy; Neck pain; Nerve blocks; Prospective study

\section{Essai de traitement avec hasardisation visant à comparer l'efficacité des blocs nerveux à répétition à la thérapie cognitive pour le soulagement des céphalalgies et des cervical- gies chroniques}

RÉSUMÉ : La présente étude prospective visait à comparer l'efficacité de deux types de traitement antinociceptif : l'anesthésie par blocage nerveux et la thérapie cognitive. Une série consécutive de patients traités par blocs nerveux a été invitée à participer à un essai d'une durée de six semaines, avec répartition aléatoire, comparant l'anesthésie par blocage nerveux à la thérapie cognitive. Soixante-huit patients sur 102, joints par

Suite à la page suivante

${ }^{1}$ Rothbart Pain Management Clinic, Toronto; ${ }^{2}$ Department of Psychiatry, University of Toronto, Centre for Addiction $8 \mathcal{B}$ Mental Health, Toronto; ${ }^{3}$ Department of Psychology, York University, Toronto, Ontario

Correspondence and reprints: Dr Peter Rothbart, Rothbart Pain Management Clinic, 16 York Mills Road, Unit 125, Box 129, Toronto, Ontario

M2P 2E5. Telephone 416-512-6407, fax 416-512-6375, e-mail reception@rothbart.com

Received for publication October 22, 2002. Accepted November 5, 2002 
téléphone, ont accepté l'offre. Les sujets ont participé à huit séances de traitement hebdomadaire. Des mesures ont été prises au départ, puis durant les sept autres semaines. Le principal critère d'évaluation consistait en la mesure de la douleur sur une échelle visuelle analogue (EVA). Les critères secondaires avaient pour objets l'anxiété selon l'Hospital Anxiety and Depression Scale et les activités de la vie quotidienne selon l'échelle Primary Care Cooperative Information Project / World Organization of National Colleges, Academies (COOP-WONCA). Au cours de la première semaine, 1 sujet sur 34 s'était retiré du groupe de traitement par blocs nerveux et 12 sujets sur 34, du groupe de thérapie cognitive. Au bout de 7 semaines, il restait 33 patients dans le groupe de traitement par

Short term use of nerve blocks for chronic pain is widely accepted. However, nerve blocks are not widely used as a palliative method for managing severe ongoing pain of the head and neck (1). Proponents of nerve blocks cite extensive patient reports of pain reduction and relief in their clinical experience, while those who downplay their palliative use cite a lack of evidence in the published literature to corroborate these clinical claims. To help address this gap in the literature, Rothbart et al (1) performed a retrospective study to assess the efficacy of repeated nerve blocks for the palliation of head and neck pain. They reported that nerve blocks demonstrated efficacy in pain relief. In addition to decreasing pain, anxiety and depression were diminished, while reported quality of life and activities of daily living were enhanced.

Nerve blocks and medications are not the only treatments that have been proposed and studied to ameliorate pain. Cognitive therapy has been shown to be effective in controlling chronic intractable pain $(2,3)$. To date, there have been few, if any, studies reporting the relative efficacy of nerve blocks and cognitive therapy in pain control. To extend previous empirical examinations of what works in pain management, we undertook a prospective, randomized comparison treatment study to compare the antinociceptive effects of repeated nerve blocks with cognitive therapy over an eight-week period.

\section{SUBJECTS AND METHODS}

As in the previous study (1), patients with cervicogenic headaches diagnosed according to the criteria of the International Association for the Study of Pain were selected (4). Their headaches were reported as daily, constant, severe and incapacitating. Nerve blocks used were occipital blocks, supraorbital blocks, paravertebral blocks and spinal accessory blocks. All patients had some or all of these nerve blocks as required to relieve their pain. The occipital blocks were performed by using a landmark at the lateral border of the trapezius muscle in its attachment to the nuchal line. This point is immediately medial to the aponeurosis connecting the origin of the trapezius and sternomastoid muscles. Four to $6 \mathrm{~cm}^{3}$ of $0.375 \%$ bupivacaine hydrochloride (Marcaine, Sanofi, Canada) was used. The lesser occipital nerve was also anesthetized by moving the injection site approximately $2.5 \mathrm{~cm}$ laterally. The paravertebral blocks were performed as described by Bonica and Butler in Wall blocs nerveux, mais 21 seulement avaient rempli les questionnaires. Quant au groupe de thérapie cognitive, 4 patients sur 22 avaient terminé l'essai et avaient rempli les questionnaires. Les scores moyens sur l'EVA dans le groupe d'anesthésie par blocage nerveux avaient diminué légèrement durant le traitement, tandis que ceux dans le groupe de thérapie cognitive avaient augmenté. Toutefois, le score moyen sur l'EVA des quatre patients restants avait diminué par rapport au score moyen enregistré au début. Les sujets qui étaient soumis aux blocs nerveux se sont montrés disposés à poursuivre l'étude s'ils étaient dirigés dans le groupe d'anesthésie par blocage nerveux mais non disposés à rester dans le groupe de thérapie cognitive tout en abandonnant leur traitement habituel.

and Melzack's Textbook of Pain (5). Marcaine 0.375\% 1.5 $\mathrm{cm}^{3}$ was used at each level. Supraorbital blocks were performed as described by Moore (6). Marcaine $0.375 \% 1.0$ to $1.5 \mathrm{~cm}^{3}$ was used.

Because the repeated nerve blocks were used only as a last resort, when all other modalities failed to provide good pain relief, the following criteria applied. The patients had undergone $\mathrm{x}$-rays, computer-assisted tomography scans and/or magnetic resonance imaging scans. Cervical facet diagnostic blocks were performed as necessary. Where positive, the patients had undergone facet joint rhizolysis. The results had been mixed, possibly because of insufficiently comprehensive radiofrequency lesioning of the medial branch of the dorsal root of the third cervical nerve (7). The patients had been treated with the usual pain medications, including nonsteroidal anti-inflammatory drugs, antimigraine drugs and antidepressants. Many patients had also been, and were still, taking opioids of varying strengths. Most patients had received psychotherapy, and some were still continuing psychotherapy. However, none had received cognitive or behaviour modification therapy; these are difficult to obtain for most patients because they are not readily available in Canada. All patients had received a course of physiotherapy at least once (and in many patients several times) during the course of their chronic pain.

It was noteworthy that five patients had been enrolled in a previous study. Many patients (including the five patients) had been receiving nerve blocks on a regular basis for seven or eight years. No adverse effects were reported by patients as a result of the previous long term palliative nerve blocks.

Potential participants were recruited consecutively by a staff nurse with no selection process beyond voluntary participation. The nurse telephoned 102 patients from a list provided by physicians who were treating patients with nerve blocks in the clinic. When 68 patients had agreed to participate, recruitment was terminated. Thirty patients in each group provided power above 0.80 . Equal numbers of participants (34) were recruited by a staff nurse for both treatment groups. The authors did not anticipate more than four dropouts per group. Assignment to the two groups was achieved by a standardized computer randomization routine. Participants were provided with a standard caution, advising them that they could withdraw from the study at any point for any reason and that this would not affect their continued treatment in any way. The participants previously had access 
to nerve blocks. However, when the data collection began in the baseline week, just before treatments commenced, only 22 individuals in the cognitive therapy group maintained their participation, while 33 of the 34 in the nerve block group began the study.

The design of this study consisted of a randomized comparison treatment study, where 67 patients who were receiving ongoing nerve blocks at either one, two or three week intervals were randomly assigned to one of two groups. Of these patients, 27 were males and 40 were females. Their ages ranged from 28 to 67 years. The first group ( 34 patients) was referred for eight weekly sessions of cognitive therapy utilizing Caudill's protocol as described in detail in her book, Managing Pain Before It Manages You (8). The second group (33 patients) continued with their nerve blocks. All patients continued with their usual other pain control medications such as nonsteroidal anti-inflammatory drugs, antidepressants, anticonvulsants or opioids. The present paper is a survey of the results of the outcomes of the two groups.

Ethics approval was obtained from the Ethics Committee of the Department of Psychology at York University, Toronto, Ontario.

\section{MEASURES}

\section{Dependent variables}

Pain: Pain was measured on a weekly basis through use of the Visual Analogue Scales (VAS) (9). The VAS consist of a single horizontal line on an otherwise blank sheet of paper with numbers running from 0 (indicating complete absence of pain) to 10 (signifying the worst imaginable pain.) Participants were instructed to mark the appropriate number on the horizontal line before each session of treatment.

Depression and anxiety: The Hospital Anxiety and Depression Scale (HADS [10]) was filled out by each participant each week to evaluate anxiety and depression levels. These have been reported to accompany chronic pain. The HADS possesses good psychometric levels of reliability and validity.

Activities of daily living: Activities of daily living weremeasured by the Primary Care Cooperative Information Project/World Organization of National Colleges, Academies (COOP-WONCA) scale (11), which consists of questions reflecting common activities that may or may not be impaired by any medical condition. It has been used in previous pain studies with good results.

Number of weeks in assigned treatment: Due to ethical considerations, participants were allowed to change their treatment at any point in time for any reason. This allowed the authors to compare the rate at which the two groups remained within their assigned treatment or switched to the other form of treatment. If one group's participants remained within their assigned modality while the other group dropped out of their assigned treatment in favour of the other, it could reasonably be inferred that those who remained were achieving adequate pain management, while those who switched were 'voting with their feet' due to less than adequate satisfaction with the control of their pain.

One might contend that the dropout rate is an invalid surrogate for treatment efficacy because it represents other factors such as fear of the unknown and desire to please the physician. On the other hand, patients might well be pleased to forgo a weekly 'needle in the neck'. Furthermore, because the cognitive therapy was delivered by a staff nurse whom the patients knew and liked, it is equally plausible that the patients wanted to stay with her to please her. Yet they dropped out of her treatment group.

\section{Statistical analyses}

Drop-out rates of the two groups: These data were initially graphed and then analyzed by a $\chi^{2}$ test to see whether the different drop out rates at the different weeks were within chance levels or statistically different. This was of primary importance becasue it is a direct reflection of an individual's choice regarding the most effective way of managing pain.

Between group differences on the VAS, HADS and COOP-WONCA scales each week: Because of the very unequal dropout rates between the two groups, it was apparent that standard analyses would miss the effect of attrition. Consequently, we analyzed each week's results with a $t$ test on the remaining participants. In light of the unequal attrition rates, this analysis represents the most valid reflection of the data from patients who remained within their assigned treatment modality.

The true error rate could be inflated in $t$ tests because of the non-normality of the data with such small numbers in the later weeks in the cognitive therapy group. However, these analyses found no significant differences between the groups with the few patients remaining in the cognitive therapy modality. Corresponding nonparametric techniques such as the Mann-Whitney test, being somewhat less sensitive, would not have found any differences.

\section{RESULTS}

The number of individuals who remained within their assigned treatment modalities is illustrated in Table 1. As is clear from these data, while all of the patients obtaining nerve blocks elected to remain with this treatment, each week, increasingly, patients in the cognitive therapy group elected to terminate that treatment and resume their nerve blocks. Several mentioned that the cognitive therapy was not helping their pain. In the nerve block group, while none dropped out, several did not complete the questionnaire at every visit.

The next question to be addressed concerned how effective the two treatment modalities were for those who remained in them. Descriptive statistics for the VAS, HADS Anxiety Scale, HADS Depression Scale and COOP. WONCA were carried out. Only the statistics for the VAS are shown (Table 2). At the end of the trial, the VAS scores were similar in both groups. It may be worth noting that 
TABLE 1

Attendance by treatment group over eight weeks

\begin{tabular}{lcrrrrrrr}
\hline Group & Baseline & $\mathbf{1}$ & $\mathbf{2}$ & $\mathbf{3}$ & $\mathbf{4}$ & $\mathbf{5}$ & $\mathbf{6}$ & $\mathbf{7}$ \\
\hline Nerve block & 33 & 33 & 33 & 33 & 33 & 33 & 33 \\
Cognitive therapy & 22 & 16 & 10 & 9 & 7 & 5 & 4 \\
\hline
\end{tabular}

TABLE 2

Visual Analogue Scale means and standard deviations by group over eight weeks

\begin{tabular}{|c|c|c|c|c|c|c|c|c|}
\hline & & & & & & & & \\
\hline & Baseline & 1 & 2 & 3 & 4 & 5 & 6 & 7 \\
\hline Nerve block group & & & & & & & & \\
\hline Means & 6.30 & 5.93 & 5.40 & 6.07 & 6.11 & 5.96 & 6.13 & 5.66 \\
\hline Standard deviation & 2.36 & 2.17 & 2.14 & 2.05 & 2.38 & 1.95 & 2.18 & 2.10 \\
\hline Number of patients & 33 & 31 & 30 & 29 & 28 & 26 & 23 & 21 \\
\hline Cognitive therapy gro & & & & & & & & \\
\hline Means & 6.40 & 6.87 & 7.45 & 7.28 & 6.33 & 7.00 & 6.00 & 6.00 \\
\hline Standard deviation & 1.76 & 1.64 & 1.51 & 1.25 & 1.97 & 1.82 & 2.83 & 2.83 \\
\hline Number of patients & 20 & 8 & 11 & 7 & 6 & 4 & 2 & 4 \\
\hline$t$ test values & 1.58 & 1.14 & 2.91 & 1.49 & 0.22 & 1.00 & 0.8 & 0.28 \\
\hline Degrees of freedom & 51 & 37 & 39 & 34 & 32 & 28 & 23 & 23 \\
\hline$P$ & 0.88 & 0.26 & 0.01 & 0.15 & 0.83 & 0.33 & 0.94 & 0.79 \\
\hline
\end{tabular}

It should be noted that individuals were kept within their original groups if they missed up to two weeks but returned to that mode of therapy, because individuals occasionally miss weeks because of life events

patients in the cognitive therapy group appeared to show an increase in their VAS ratings because dropping out occurred. For the most part, there were no statistically significant differences between the two treatment modalities in antinociceptive efficacy, as reflected in those participants who remained in the study. However, as noted above, it was a decided minority of participants who chose to remain with this form of treatment while the increasing majority chose to revert to nerve blocks in succeeding weeks.

\section{DISCUSSION}

There were two main findings in this prospective study. The first was that individuals in the cognitive therapy group overwhelmingly chose to end participation in that modality and switch to the nerve block treatment. The second finding was that for the minority of patients who chose to remain in the cognitive therapy modality, reported mean pain levels were no different from the mean of the nerve block group. This raises the interesting possibility that some individuals may derive equivalent pain relief from cognitive therapy, or possibly placebo, as others obtain from nerve blocks. If our results are replicated in larger studies, it may be worthwhile to delineate which individuals may be optimally treated by these respective techniques. Clinically, one observes that some pain patients do not feel able to assume responsibility for control of their pain, but are most willing to assign the task to the treating professional. Such patients would probably be least comfortable with cognitive therapy, where control would reside internally. Alternately, some have a clear aversion to having needles stuck into their necks, and may be more responsive to cognitive therapy.

Our findings have one significant limitation that must be considered before firm conclusions are drawn from these data. This relates to the participants' all having had prior experience with nerve blocks. This experience may have biased them in terms of expectations and previous level of comfort with a successful treatment modality. Consequently, a further study of this type would require a prospective design with naïve patients.

On a technical note, in a previous study, we demonstrated dramatic drops in VAS pain ratings with nerve blocks that far exceeded the more modest pain reductions evidenced by both treatment modalities in this study (1). However, it must be noted that in our earlier study, VAS ratings were obtained approximately within $24 \mathrm{~h}$ of the block, when pain relief was optimal (1). Conversely, in the current study, VAS ratings were obtained immediately before the next treatment session, whether via cognitive therapy or nerve blocks.

Our clinical experience from patient reports is that the patient has good pain relief for one to four days and the pain then slowly begins to increase over the ensuing days. Thus, time of measurement is an important if sometimes masked variable in pain management studies of nerve blocks. The protocol of measuring pain relief at the end of a treatment week appears to obscure the maximal effect that can be associated with an acute intervention by nerve blocks for pain. 


\section{REFERENCES}

1. Rothbart P, Fieldler K, Gale GD, Nussbaum D, Hendler N. A descriptive study of 100 patients undergoing palliative nerve blocks for chronic intractable headache and neck ache. Pain Res Manage 2000;5:243-8.

2. Turk DC, Meichenbaum DE, Genest, M. Pain and Behavioural Medicine: A Cognitive Behavioural Perspectives. New York: Guilford Press, 1983.

3. Turk DC, Rudy TE, Sorkins BA. Chronic pain: Behavioural conceptualizations and interventions. In: SM Turner, KS Calhoun, HE Adams, eds. Hand Book of Clinical Behavioural Therapy, 2nd edn. New York: Wiley, 1992.

4. Merskey H, Bogduk N, eds. Classification of Chronic Pain: Description of Chronic Pain Syndromes and Definitions of Pain Terms, 2nd edn. Seattle: IASP Press, 1994.

5. Wall PD, Melzack R, eds. Textbook of Pain. Edinburgh: Churchill Livingstone, 1984.
6. Moore DC. Regional Block: A Handbook for Use in the Clinical Practice of Medicine and Surgery, 4th edn. Springfield: Charles C Thomas, 1979.

7. Lord SM, Barnsley L, Wallis BJ, McDonald GJ, Bogduk N. Percutaneous radio-frequency neurotomy for chronic cervical zygapophyseal-joint pain. N Engl J Med 1996;335:1721-6.

8. Caudill M. Managing Pain Before It Manages You. New York: Guilford Press, 1995.

9. Carlsson AM. Assessment of chronic pain: Aspects of reliability and validity of the visual analogue scale. Pain 1983;16:87-101.

10. Juang KD, Wang SJ, Lin CH, Fuh FL. Use of the hospital anxiety and depression scale as a screening tool for patients with headaches. Chung Hua I-Hsueh Tsa Chih 1999;11:149-55.

11. Dartmouth and Coop. Dartmouth Coop Functional Assessment Charts/Wonca. Dartmouth/Coop Project, 1995. 


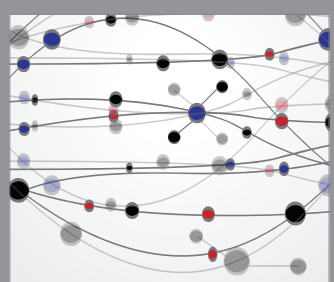

The Scientific World Journal
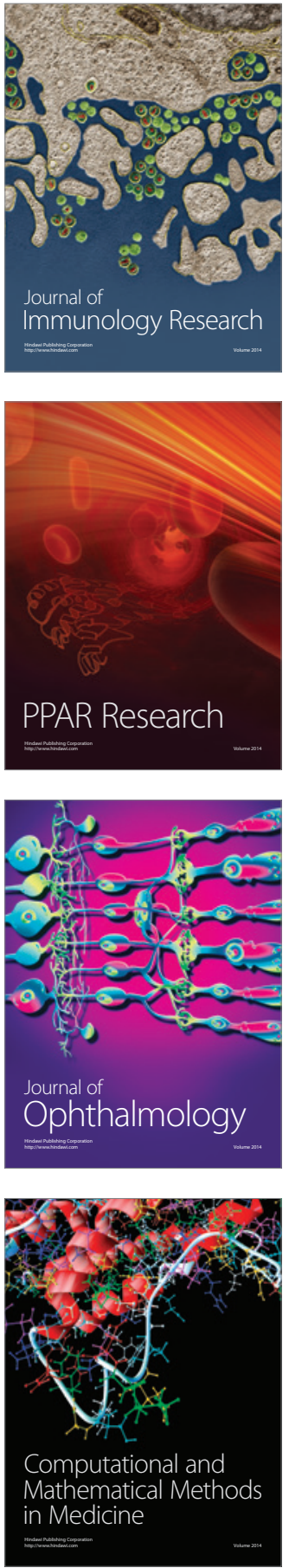

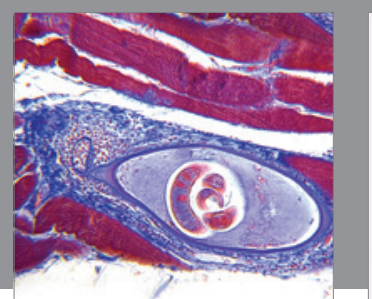

Gastroenterology Research and Practice

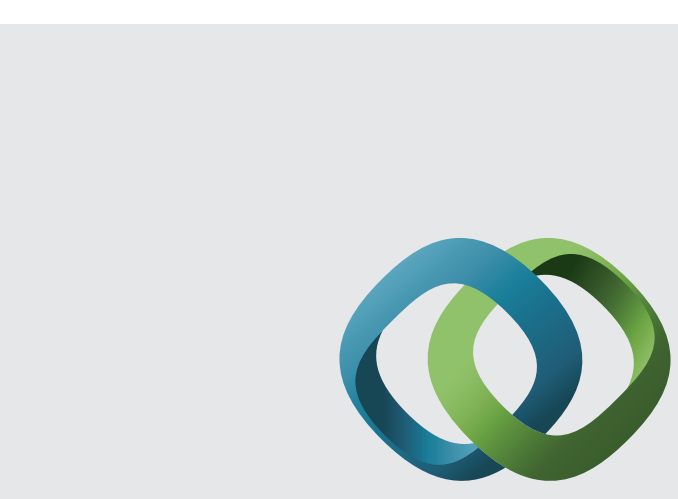

\section{Hindawi}

Submit your manuscripts at

http://www.hindawi.com
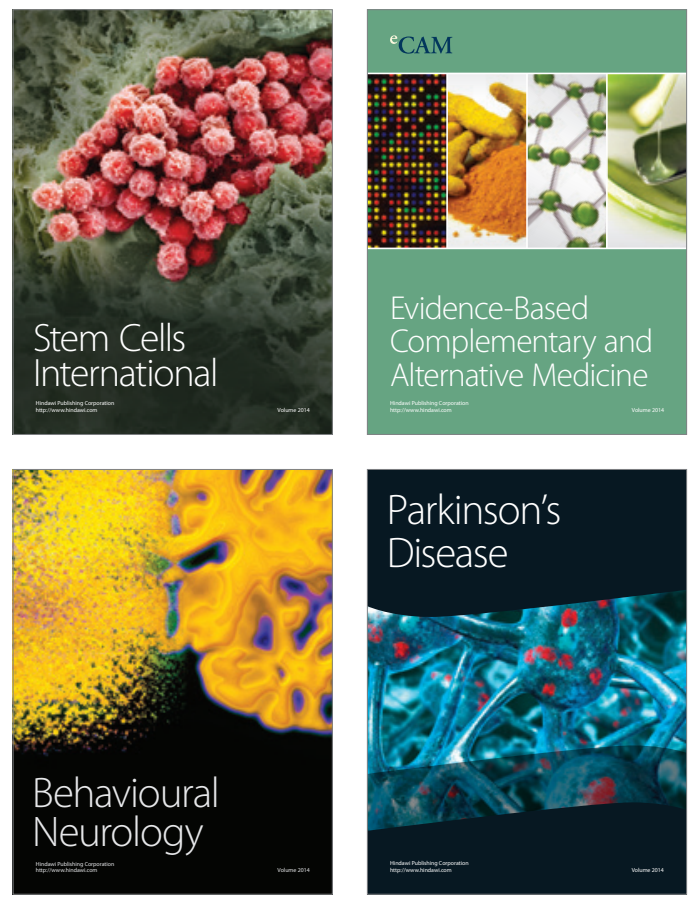
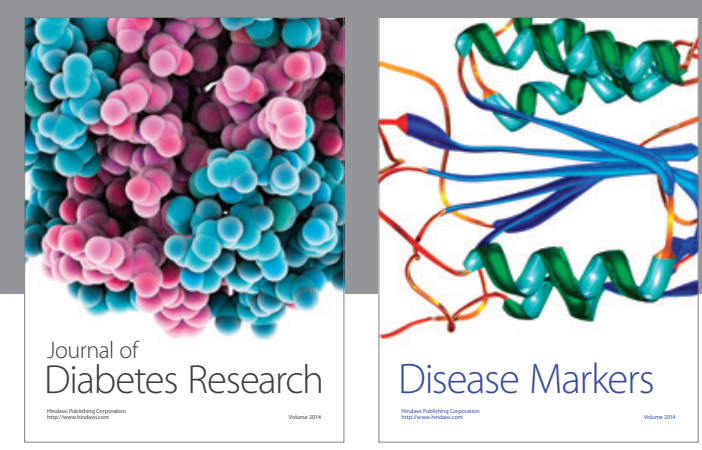

Disease Markers
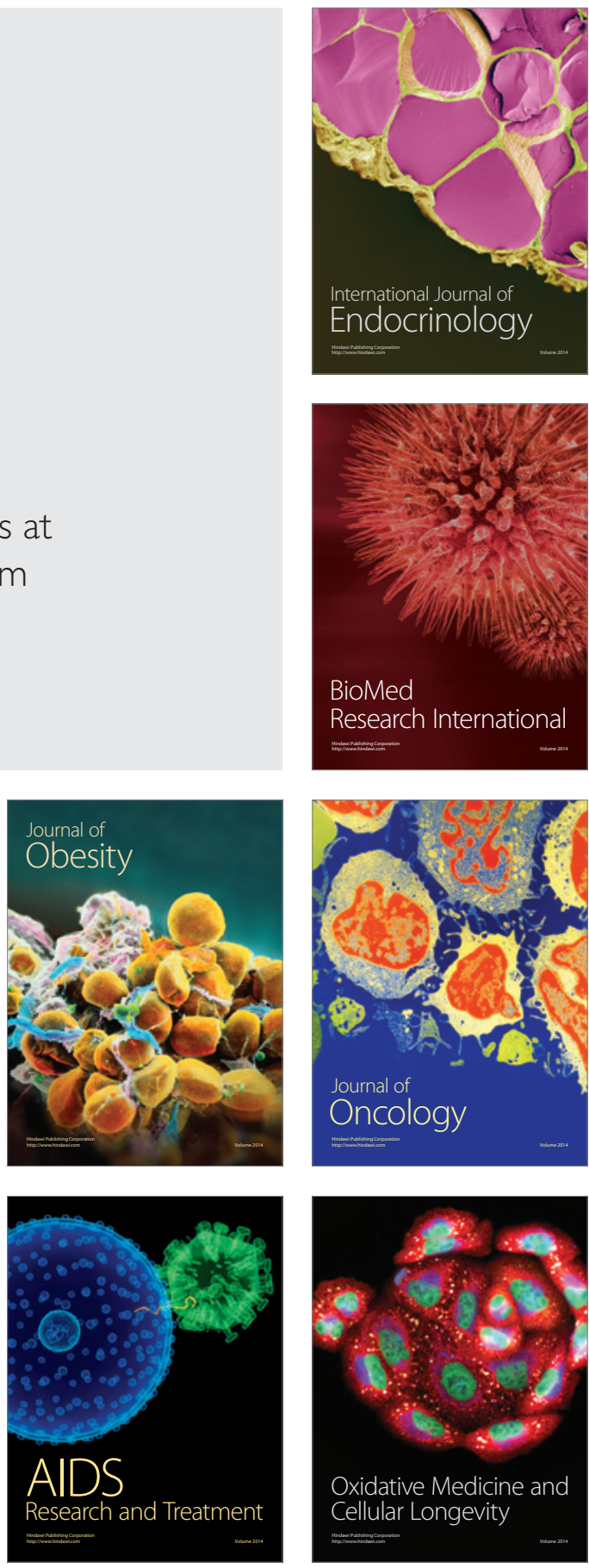